\title{
Language Learning Enhanced by Music and Song
}

\author{
Hilda F Israel \\ Nelson Mandela Metropolitan University, South Africa
}

\begin{abstract}
A song is poetry set to motion. A song in a second language enhances the learning of that target language. This study confirmed that English second language learners were inspired by the singing of songs and music to achieve better in their study of literature, as well as other aspects of the target language. Learners were overwhelmed by the high standards and analytical thought skills required in the understanding of poetry as an aspect of their English curriculum. Lack of interest quickly set in, until the teacher decided to motivate them through the use of contemporary songs as a teaching methodology. The skills learned were then transferred to the study of other aspects of the language curriculum. The application of song and music as a teaching and learning classroom motivation was affirmed, resulting in creative and enhanced language performance.
\end{abstract}

\section{Introduction}

'If music be the food of learning, play on' (with apologies to Shakespeare). There are times when the language teacher has to be very creative indeed, or else both content learning and the throughput rate of learners suffer.

The setting of this case study was a postdemocratic, secondary school in KwaZulu-Natal, South Africa (SA). Originally for South Africans of Indian descent only, it included all black learners living in the local area at the time the study was undertaken. The class was Grade 11, a mixed ability group of learners mostly from the local informal or shack settlement. Some were definitely at-risk learners. Many had just a basic knowledge of the English language. The teacher's task was to teach English literature, one aspect of which was poetry analysis. After foundation lessons, and a review of two poems, she knew that traditional methodologies and evaluations were not appropriate and had to change.

"Turn the beat around..." by Gloria Estefan became the newly adopted 'teaching methodology'. Music and song, whether pop, rock, kwaito, rap, Rhythm \& Blues, hip-hop, house... healed the world and made it a better place for these learners. The teaching and learning lesson plan and assessment was simple, but experimental.

The Plan: Learners chose one song (for example, the rap version of Just the two of us by Will Smith; Beat It by Michael Jackson). The teacher chose one song (for example, Turn the beat around by Gloria Estefan; California Dreaming by The Mamas \& Papas) and the third was mandatory, the SA National Anthem, Nkosi Sikelel'i-Afrika. Then followed the prescribed poetry list, but learning now was based on how the music lyrics were analysed. The anthem was included to inspire national pride and citizenship.

Methodology: The introduction lesson was a marketing strategy. The class was moved to a room far away from the main teaching block and music welcomed the learners for about fifteen minutes. Popular music, kwaito and rap music was played at high volume to make an impact on the young people. Singing the lyrics and dancing was a natural response from them. Students commented that this classroom had an "electric mood" and that learning "had a vibe". One student notably added that this was "Africa in the classroom". No learner stood still... until the words of the lyrics were transferred onto the overhead projector screen. Then the teaching and learning began. Actually, this was when the teaching and learning continued.

The sudden dawning that the music they were enjoying was actually a poem in motion seemed to fascinate the students. The language did not matter because they sang in English and African languages. They accepted that they were singing a poem set to music. It was this critical moment that transformed what they thought was a music experience into an education situation, a teaching and learning situation. Music was the motivation behind the learning. Words were analysed and meanings debated. Rhyme was clarified. Figurative language was identified and discussed in the context of the text. The lesson was closed with five more minutes of music. No learner wanted to leave the classroom. The beat had turned the learning experience around. More importantly, the young people wanted to learn, they were motivated to engage with the words of the lyrics.

The learners were thereafter allocated three tasks: 
- A writing assignment based on the analysis of the 3 songs as poetry.

- A small group presentation of any 2 of the 3 songs as their oral assessment.

- A full discussion of what the learning process meant to them as individuals and as a group.

By three weeks later, all English language lessons were becoming increasingly boisterous in a positive way. Five minutes of each lesson was devoted to a progress report on "Our Production": music motivated them to own the assessment tasks. Students wanted to learn. The motivation was clearly intrinsic, with visible benefits in other learning areas as well. Grammar classes were not tedious any more. Shakespeare was visualised as a poet too, exposing them to more imagery analysis. The learners' oral presentations became more ambitious than expected, with music, song, costume and videotaping all being integrated into the task. Funds were even raised to get $\mathrm{T}$-shirts for their groups.

The objective in using music was to motivate the teaching and learning of poetry. Not only were the lyric productions beyond expectations, but language ability in the written task improved as well. The poetry lesson changed. Each poem now had the potential to be sung, while some learners proved adept at converting them to rap format. The teacher realised that analysing the poem was now more accessible, more possible. Music had made the environment more learner-friendly. Music had motivated the learners to go beyond their language limitations and respond to lyrics as poetry, and poetry as lyrics. Music brought them together despite diverse racial, cultural, economic and social differences. Music made better learners of the at-risk individuals. What was confirmed was that music as an innovative teaching and learning intervention had worked.

The poetry analysis section of the curriculum thereafter merged with the oral presentation section. The fact that all of this was being performed in a language other than their mother-tongue seemed irrelevant to many of the learners. "Editing" became their new "buzzword". For many, their confidence in using their limited knowledge of English visibly grew. The writing task produced efforts that ranged from mediocre to outstanding. Evidence of research on the national anthem brought national history and pride into the learning process. One group videotaped themselves performing their song as part of their presentation. Another did a stage choral production, with all of the learners wearing red $\mathrm{T}$ shirts and jeans.

The critical analysis of the whole music-asmotivation process was an unexpected development, being exposed when learners shared their personal reflections on the innovative teaching process. The hidden curriculum emerged as questions focussed on personal learning growth. Questions included the following: What did it take to be a team player? Why did tensions arise at times? How did each contribute to the final written and oral product? Why did they resent the "lazy" learner who did not contribute as expected? Critical thinking was being applied without the learners even recognising it, or knowing that they were even capable of it. Music motivated this enthusiasm and desire to learn.

Today, when the teacher meets some of the learners from her English class, the conversation is not about how much they have progressed, but about how music helped them to enjoy their language lessons. And they proudly add that, when they sing the national anthem, they do not need to look at the words anymore.

\section{Music and Learning}

The case study indicated that music enhances one's skills in academic achievement, self esteem, national pride, identifying with one's culture and general self confidence. Music is a means of communication. It crosses all barriers - language, culture, belief systems, age, gender and nationality. It is an innate part of a person's being. Depending on taste, it soothes and relaxes, inspires and motivates. Used carefully in the learning situation, it can turn the beat of the learning process around.

In the SA Curriculum, the Arts and Culture Learning Area states that music creates opportunities for a learner to: develop a healthy self-concept; work as individuals; acknowledge and develop the diversity of South Africa's cultures and heritage; develop skills in art; respect human value and dignity; develop life-long learning skills [17]. As teachers of diverse primary and high school learners, educators need to identify how we can use music to motivate the learner. How can we tap into their learning styles, limitations and strengths?

Eady and Wilson [4] confirm that various studies prove that music does contribute to a learner's academic achievement, motivation and creative development. They conclude that music helps one to learn more, and more effectively. Music contributes to all of education. The learner benefits by enhancing key developmental goals such as selfesteem and creativity.

Learners achieved better scores when music was part of their social studies. McTeer and Bailey [8] reinforce the thesis that music motivates learning in other disciplines through their research on student attitude towards history and subject knowledge 
matter. An experimental group of senior high school students were exposed to contemporary music to rejuvenate their history class. The control group was taught using the lecture-discussion method. With all other variables being constant, the outcome was that in the area of attitude and subject matter knowledge, the group exposed to music as motivation scored better averages.

Research conducted by Weisskoff [22], as cited in Eady and Wilson [4], supports the premise that music influences learning in core subjects and helps to achieve the core goals of learning. He compared two learning situations: learning in language arts with music and without music, with his focus being on task performance and continuing motivation. Did the presence of music make any difference or not? The outcome was that those who learned in the music situation scored very much higher in terms of sustained motivation, seen in the tendency of learners to continue working on tasks after the initial motivational lesson. Task performance was not improved by the music motivation. Music was neither a positive force nor a distraction in task achievement. He further clarified that background music during a learning task does not enhance achievement. However, Weisskoff [22] proves that music as motivation does work for learners. The research confirmed that there is a solid relationship between music and continuing motivation: unmotivated learners became motivated because of the presence of music. The SA case study, despite its unusual and innovative context, confirmed these findings.

An aspect that cannot be ignored is the massive technological advancement in music today. Learning tasks involving technology provide excitement and innovation for the student. Moore [11] explains that Musical Instrument Digital Interface (MIDI) technology allows learners to create, edit and recreate music compositions, making the task more personal. Divergent thinking is rooted in such tasks. The creative potential of the learner is clearly unlimited with such technology available at school.

\section{Music and Language Learning}

Language acquisition has a profound relationship with music in that they can both develop and support each other. Research cited reveals a positive interdependence when music is used with much reflection and planning in the language classroom. "Melodic recognition, contour processing, timbre discrimination, rhythm, tonality, prediction, and perception of the sight, sound, and form of symbols in context are required in both music and language" Stansell [18]. The obvious implication now lies with the language teacher, and linguistic researcher, to find methodologies that can be practically applied in the classroom, ways that would make the learning of language more effective. Traditional language teaching methods have to be reviewed, and music introduced as one means of further enhancing learning. Fluency would be the outcome of merged methods of teaching and learning, together with motivated learners, improved vocabulary development, use of vocabulary in context and communicative confidence, as evidenced by the case study cited. There was positive impact on the four key language learning areas: listening, reading, writing and speaking.

"Researchers over the last twenty years have made astounding advances in the theory of language acquisition. Many find the pedagogical conjoining of language and music compelling" Stansell [18]. When the case study learners colloquially talked of their learning having a vibe, they expressed what Stansell [18] more academically stated: "The universal element of music can make the artificial classroom environment into a 'real' experience and make new information meaningful, bringing interest and order to a classroom."

Moticoe [13] wrote the newspaper headline: Music that speaks where language fails. The article which followed spoke of the musical journey of a group of musicians called Ntjapedi. They were attracting much interest with their new style of music, singing in Sesotho and combining jazz, poetry and soul to create a sound that transcended language and cultural barriers. Their listeners came from various language groups in SA, proving that music speaks and acts across all boundaries.

As educators, how can one define the relationship between language learning and music? Oats and Grayson [15] write of language acquisition being rooted in phonology, morphology, syntax and semantics. Connections in the acquisition process can be seen as follows:

Levels of Language Learning

1. Phonology: consists of symbols that represent the sounds of language.

2. Morphology: form of words establishes meaning and grammatical function.

3. Syntax: order of words constitutes sentence formation.

4. Semantics: vocabulary creates meaning and understanding.

If music can be seen as a language as well, then parallels can be drawn between the acquisition processes applicable in language learning and music learning. 
Another study conducted by Horn [6] also confirms that music is a form of language, using tones, pitch, timbre and rhythm as a universal language. Both language and music are 'communicative modes, aurally and orally transmitted, containing phonetic, syntactic, and semantic components, develop early in life and are socially interactive media.' Horn [6] adds that music enriches one's vocabulary and teaches articulation and pronunciation. She notes that music plays a vital role in the teaching of English as a second language, emphasising that to be 'able to learn, understand and experience music and language, the learner should have well-developed listening skills.' Developing the ability to listen enables learners to learn the basic skills of language: listening, speaking, reading and writing. Horn [6] suggests that music should be used to encourage learners to listen in a mentally active and analytical way, adding that 'In learning the language of music, just as in learning any language, learners need to listen to the language and its sound patterns before they are able to use it.' Clearly, listening ability is basic to the teaching and learning of reading and comprehension, being therefore a central component of language acquisition, education and social development. In language learning, studies reveal a correlation between the teaching of music and reading. "Both use a symbol structure that can be decoded into sounds that have meaning. Visual and auditory discrimination are required in both subjects and are oriented to a left-to-right framework" Eady and Wilson [4]. The similarities occurring in the learning process, during the acquisition of both language and music skills, reveal remarkable benefits especially to an English Second Language (ESL) learner. Most of the learners in this SA case study were ESL learners.

Reading music is another form of literacy. The teaching methods may be similar, but because more enjoyment comes from music, the learner is motivated to progress on to other forms of literacy. Supporting this argument is Cohen-Taylor [2], who established that when primary school learners were given contemporary song lyrics to read, they thereafter reacted positively to other printed material. Their lack of motivation was broken by the introduction of contemporary music that they recognised. He points out that reading skills can be more effectively taught through song lyrics.

Note should be taken of a study by Murray [14], who actively teaches French using song lyrics. Her point is that most people spend almost $50 \%$ of their time listening, a critical skill in second language acquisition. Listening formed a vital part of the case study, and expanded into assessment of communication and language performance for each learner. Such evaluation included the meaning of key words, why the singer chose to use them, their application in poetic forms and the idiomatic turn of phrase applied. Like in the case study, Murray [14] analysed songs as poems, thus expanding the student's grammar and vocabulary, developing skills needed for learning the target language in greater depth. Pronunciation was also improved, because her students listened to the beat, rhythm, flow or accent that was used. Students were also able to study the differences between the oral and written forms of the target language.

Learning a language through lyrics in the target language will motivate students because they define who they are through their own culture, and through the music that they enjoy. Through music as a teaching methodology, students are further exposed to foreign language and culture, making the learning experience far more integrated than perceived. Language acquisition evolves into culture and communication acquisition.

Mora [12] believes that music and language should be often used in the teaching of English as a Foreign Language. Song introduces the repetition of words and phrases, and such repetition enables the brain to remember learned content. She points out that repetition in Russian is idiomatically referred to as mat' ucheniya, the mother of learning. Mora [12] found that repetition through song worked: "The musicality of speech has an effect not only on the pronunciation skills of EFL students but also on their entire language acquisition process." This ensures that in addition to attending class, completing tasks and speaking out loud, the song enables rehearsal of language that has been learned. Studies by Schunk [16] support this conclusion: children who heard an intervention text sung had a significantly higher vocabulary gain over children who only heard it spoken. They averaged 6.5 words learned, over the text group's 2.5 words. Clearly, song and music are effective language teaching methodologies. Medina [9] further encourages vocabulary development through oral stories, but found that learning was enhanced when songs were used as a medium for the story. ESL educators should consider using song more often, and more consistently, in the classroom.

Eady and Wilson [4] suggest the following methods to teach reading and language skills:

- activities using word cards featuring favourite words of songs;

- forming new sentences from words in favourite songs;

- guessing first lines of songs, with the teacher giving word configuration clues, and

- creating crossword puzzles in which the entries are words in song titles. 
It is common knowledge that African peoples have a natural sense of rhythm. For the South African ESL educator, this strength should be exploited and developed into a teaching tool that supports the learning of language. Horn [6] recommends:

- classroom activities that use music as a complementary method because it makes full use of visual, auditory, movement and tactile senses;

- $\quad$ songs used should be short, rhythmic, simple and with a catchy melody;

- $\quad$ schools having music-educated teachers, music venues and suitable instruments and equipment,

- well organised music programmes that support teachers;

- the integration of music into all aspects of the curriculum;

- mother-tongue instruction at pre-school to form the basis of later learning;

- that parents be encouraged to improvise music/sound related activities with their children, for example, family singing, listening to music and doing household chores to music, and

- that parents be involved in their child's taste in radio and television to guide the kind of music and language that influences their listening and speaking.

Monitoring Academic Progress of students (MAP) was a project where thirty primary school learners attended workshops on music, poetry and reading selections with the aim of improving their self-concept and reading achievement. They worked together in writing song lyrics. Songs and reading passages chosen encouraged learners to think of themselves and others in a positive fashion; they wrote their own poetry and presented this in readings and on posters. Speaking and reading skills were being learned. Concentration and memory were tested through such exercises. The outcome confirmed that reading and listening skills taught this way were very effective, as recorded in Hadley and Hadley [5].

Murray [14] aptly points out that songs "provide us with a window into a world that is not our own, a world that we glimpse and remember thanks to the power of music." Music is an integral part of our lives today - it's in our cars, homes, cell phones, MP3s, shopping malls, radios, television programmes. Students walk around campus with earphones plugged on for the entire day - listening to their personal music selections. This is an ideal context for the language teacher, who should explore as many ways as possible to formally integrate music into the classroom. The teacher can expand on this by including the understanding of culture through music.

The literature cited justifies the use of song and music in ESL teaching. However, the integration should be on a regular, planned basis for optimum effect. Assessment of language performance should also include song and music where applicable. Exponents of traditional text book methods of language teaching may consider this revolutionary, but need to evaluate the hidden curriculum before writing it off. Stansell [18] sums this up succinctly when he states that the musical method means having fun with language and letting words come easily; this identifies with communicative language learning methodology, which includes social interaction, small groups and peer discussion. Music does bring relief from vocabulary tests and grammar drills. Today, the use of song and music offers a more natural and holistic way of learning language.

Horn [6] points out that singing songs, as was done in the case study, provides practice in language usage and music. When speech and music are combined to produce singing, both hemispheres of the brain have to actively co-operate: left brain for speech; right brain for music. Language seems thus to have an underlying rhythmic principle, integrating and harmonising speaking, listening, music, speech patterns, pitch, beat and timing. Her conclusion is that since learners are taught through English as their medium of instruction, the problems they experience in language acquisition may be addressed through the use of music as a teaching tool. Music may be used to develop the language competence of ESL learners. Music and singing enables the speaking of English in a more relaxed and non-threatening context. The use of song picture books allows the learner to see, sing and learn the language. Music allows for the learning of language structures and words, thus improving conversational and social communication skills.

When it comes to language learning, music can also be used for group work in reading exercises. The introduction of jazz enables improvisation ideas that may well impact on other aspects of language learning. Vande Berg [19] adds that jazz improvisation permitted every child to actively participate in a non-threatening context, since verbal exercises are not seen as right or wrong. Exercises can be read to a steady beat in the classroom, with pitch, rhythm and volume being altered in jazz-like ways. Language learning becomes thus an enjoyable experience because the activity motivates the student.

Curnow [3] clarifies that a basic function of the teacher is to encourage a student to use the skills he/she has learned in a creative manner. One way 
would be through studying song lyric improvisation. If the teacher had to merge improvisation and reading, there is every possibility that students can 'discover new insights when transforming and rearranging language to syncopated beats and sound and composition projects. Various writers on creativity argue that musical improvisation and composition should be as routine as writing an English composition...', as stated in Eady and Wilson [4]. The goals would be integrated: to encourage involvement in creative musical arrangements; to develop self-evaluation skills and to critically analyse one's work. Improvisation involves creative thinking which is a dynamic mental process that alternates between divergent (imaginative) and convergent (factual) thinking, Webster [21].

One prominent feature of the case study was student interest in rap and hip hop formats of music. Merina [10] confirms that poetry teaching is stimulated by rap. Learners can recite poetry traditionally and set the poem to rap beats. Rap poetry excites learners because it is very similar to what they have on their iPods, CDs, cell phones and black berries. They enjoy this because they identify with rap culture and communication. However educators may feel about rap and hip hop, they are here to stay. Since rap music is unifying an entire generation of various cultures, it should be exploited in the classroom as part of a multicultural approach to education. Positive lyrics can be improvised and composed to a driving beat, to add interest in lessons to be learned.

Students argue that learning English is vital for their career success, besides being a status symbol of their progress. Learners at urban schools prefer to speak English instead of their mother tongue. This case study confirmed, to some extent, that despite music providing motivation in the learning and understanding of English, other factors also contributed to general academic success. If early teaching and learning is not solid and supported, then this has a detrimental effect on further learning through high school and university. Experience as a language teacher confirms that meaningful learning is established only when new concepts are linked to relevant anchorage points in one's cognitive structure, so understanding English is a prerequisite if it is to be used as a medium of instruction. The learner's cognitive development is thus directly related to his/her language development.

\section{Music and Motivation}

Music inspires and soothes, and people who are musically talented seem to have an enhanced aptitude in the learning of foreign languages. This is based on an "advanced ability in perceiving, processing, and closely reproducing accent" Stansell [18]. Both music and language are ways through which humans communicate through sound and gesture.

How students are motivated and how they perform in school has basic impact on their selfconcept. Low self-esteem results from poor academic results, drug problems, violence, pregnancy, criminal behaviour, dysfunctional family background, HIVAIDS, xenophobia and poverty, among many other factors. Research done by Viljoen and Mole [20] confirm that behaviour problems can be further attributed to the stresses of second language learning. Learners feel stressed by the increasing demands being made on them, and feel left out of the "main stream." Assessment tasks are challenging and grades earned depressing.

In the education context, it is critical that the educator recognises the relationship between music, motivation and learning. This case study provides evidence that music actively motivated students to believe in themselves, to take on seemingly difficult learning tasks and to gain confidence. It became clear that being competent in one area and feeling good about one's performance in this area, actually helped learners to cope with weaknesses in other areas. The premise is that if one is good at music, this strength makes up for one's lack of sport, language, academic or social skills. This case study provides actual evidence that music gives academically unsuccessful students a place to succeed. A positive musical self-concept thus makes up for poor academic self-concept. Music then, is a tool for motivation in learning. Music can be effectively used to achieve non-musical goals. The Tanglewood Declaration of 1968 calls for music to be placed at the core of the school curriculum, arguing that 'Music and other fine arts, largely nonverbal in nature, reach close to the social, psychological and physiological roots of man in his search for identity and self-realization' [1].

This case study involved students singing their chosen songs, creating in a sense a choral music experience. Hylton's [7] investigation exposes the relationship between choral singing and self-concept, with students rating the experience highly on the following statements:

1. to help me get to know myself better;

2. to feel more at ease, and

3 . to help me to be at peace with myself.

Students were able to mix more on a social level, thus influencing their social self-concepts as well. The case study emphasised that music and singing as integral parts of learning English as a second language cannot be ignored. Not only were students 
motivated, but they actually enjoyed learning in a relaxed, non-competitive learning situation. The singing enabled learners to discover language structures and new words incidentally. They were then able to use them in communicative contexts.

In conclusion, a positive attitude and motivation are essential when learning a second language. Experience of success is vital to the learner's progress, providing the motivation for the next step. The educator's planning and vision has to determine this, ensuring that the learner, as an individual and as a member of a group, is set a task that is realistic, challenging and keeps him/her involved to completion. Using song and music as an innovative teaching tool meets such requirements.

\section{References}

[1] Choate, R.A. 1968. Documentary report of the Tanglewood Symposium. Reston, VA.1-4. http://homepage.mac.com/wbauer/hpmused/archive/tangle wood.html\# declaration. (accessed February 5, 2010).

[2] Cohen-Taylor, G. 1981. Music in language arts instruction. Language Arts, 58 (3), 363-368.

[3] Curnow, R. 1987. The jazz experience: A curriculum for creativity. New Ways for New Days in Music Education, 3, 12.

[4] Eady, I and Wilson, J.D. 2004.The Influence of Music on Core Learning. Education, 125 (2), 243.

[5] Hadley, W. H., and Hadley R. T. 1990. Rhyme, rhythm and reading for at-risk students. Thresholds in Education, $16(2), 25-27$.

[6] Horn, C.A. 2007. English second language learners: using music to enhance the listening abilities of grade ones. Masters thesis. Unisa. http://etd.unisa.ac.za/ETD$\mathrm{db} /$ theses/available/etd09212007.133117/unrestricted/disse rtation.pdf.(accessed February 5, 2010).

[7] Hylton, J.B.1981. Dimensionality in high school students participants' perception of the meaning of choral singing experience. Journal of Research in Music Education, 29, 287-303.

[8] McTeer, H. J. and Bailey, R. T. 1980. The effect of the teaching technique using popular music upon students' attitudes toward history and subject matter knowledge. A study conducted at South Cobb High School, Austell, GA. April Dialog, ERIC, ED 196749.

[9] Medina, S.L. 1993. The effects of music upon second language vocabulary acquisition. National Network for Early language Learning, 6 (3). http://www.oocities.org/ESLmusic/articles/article01.html (accessed May 30, 2013).
[10] Merina, A. 1993. Sounds of our times. Rap: tool or trouble. NEA Today, 11 (8), 1.

[11] Moore, B. 1992. Music, technology, and an evolving curriculum, NAASP Bulletin, 76 (544), 42-46.

[12] Mora, C.F. 2000. Foreign language acquisition and melody singing. ELT Journal, 54(2), 146-152. http://eltj.oxfordjournals.org/content/ (accessed May 29, 2013)

[13] Moticoe, M. 2008. Music that speaks where language fails. The Times. 21 April 2008.

[14] Murray, S.K. 2005. Learning a Second Language through Music, Baylor University, Academic Exchange Quarterly, 9 (2), http://www.questia.com/library/1G1136071099 (accessed May 27, 2013).

[15] Oats, J. and Grayson, A. 2004. Cognitive and Language Development in Children. The Open University. London. Blackwell Publishing Ltd.

[16] Schunk, H. A. 1999. The effect of singing paired with signing on receptive vocabulary skills of elementary ESL students. Journal of Music Therapy, 36, 110-124.

http://voices.yahoo.com/the-music-song-esl-instruction423127.html (accessed May 28, 2013).

[17] South African Department of Education. 1997b. Discussion Document: Curriculum 2005. Pretoria. Department of Education.

[18] Stansell, J.W. 2005. The Use of Music for Learning Languages: A Review of the Literature. University of Illinois at Urbana-Champaign. http://mste.illinois.edu/courses/ci407su02/ (accessed May 27, 2013).

[19] Vande Berg, K. 1986. Teaching jazz/show choir: The team approach. Georgia Music News, 47 (1), 39-41.

[20] Viljoen, C. and Molefe, R. 2001. Language related problems of limited English proficiency learners in Grade 1. South African Journal of Education. 21(2):121-127

[21] Webster, P. 1990. Creativity as creative thinking. Music Educator's Journal, 76 (9), 22-28.

[22] Weisskoff, R. S. 1981. The relationship of pop/rock music to children's task performance and continuing motivation in language arts instruction. Unpublished doctoral dissertation. University of Connecticut, Hartford, CT. 